Portland State University

PDXScholar

7-6-2021

\title{
Spread Like Wildfire: Assessing the Utility of Local Facebook Groups to Inspire Citizen Communication During a Disaster
}

Colby Riehl

Portland State University

Follow this and additional works at: https://pdxscholar.library.pdx.edu/open_access_etds

Part of the Social Media Commons

Let us know how access to this document benefits you.

Recommended Citation

Riehl, Colby, "Spread Like Wildfire: Assessing the Utility of Local Facebook Groups to Inspire Citizen Communication During a Disaster" (2021). Dissertations and Theses. Paper 5719.

https://doi.org/10.15760/etd.7592

This Thesis is brought to you for free and open access. It has been accepted for inclusion in Dissertations and Theses by an authorized administrator of PDXScholar. Please contact us if we can make this document more accessible: pdxscholar@pdx.edu. 
Spread Like Wildfire:

Assessing the Utility of Local Facebook Groups to Inspire Citizen Communication During a

Disaster

by

Colby Riehl

A thesis submitted in partial fulfillment of the requirements for the degree of

Master of Science

in

Communication

Thesis Committee:

Lee Shaker, Chair

Lauren Frank

Cynthia-Lou Coleman

Portland State University

2021 


\begin{abstract}
As traditional sources of local news and information decline, community-oriented social media services (e.g. Nextdoor, Facebook groups) are expanding (Masden, Grevet, Grinter, Gilbert, and Edwards, 2014). Thus far, community-oriented social media use remains relatively understudied. Not only do we not understand how citizens utilize these resources, we are also generally unaware of the content that they create and access using them. A survey of residents of Oregon City, OR and its environs, which were impacted by the Oregon wildfires of 2020, was conducted to assess the differences among citizens who use a local Facebook group \& those who do not. This survey includes the Citizen Disaster Communication Assessment (CDCA) battery developed by Spialek and Houston (2018) as well as community resilience and neighborhood belonging scales developed by Pfefferbaum, et al. (2015) and Ball-Rokeach, Kim, and Matei (2001). Results indicate that citizens who utilize locally-oriented Facebook groups during and after a disaster exhibited stronger perceptions of community resilience and neighborhood belonging than citizens who do not use such groups. These results have theoretical implications for CIT and communication ecology research, but they also put forth practical implications for local leaders and organizations.
\end{abstract}




\section{Dedication}

To my family, friends, and community, who supported me on this journey, I extend a hand of gratitude. While fraught with trials and tribulations, your continued support provided me the motivation to continue. I am forever grateful. 


\section{Acknowledgements}

With acknowledgement of the Native peoples on whose land we have had the opportunity to live, learn, and grow including the Multnomah, the Clackamas, and other Indigenous communities of the Pacific Northwest. Additional acknowledgements to Dr. Lee Shaker, Dr. Lauren Frank, and Dr. Cynthia-Lou Coleman for mentoring me through this journey and providing me the tools and skills to complete this project. 


\section{Table of Contents}

Abstract.

Chapter 1

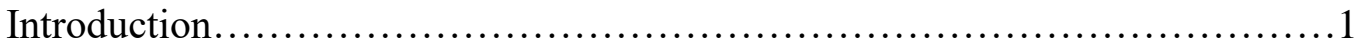

Chapter 2

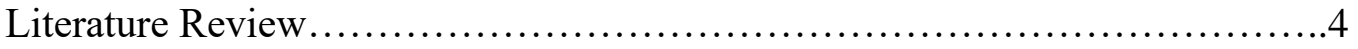

Chapter 3

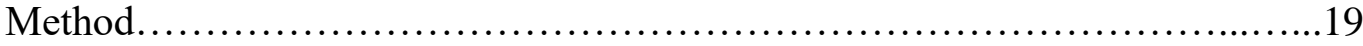

Chapter 4

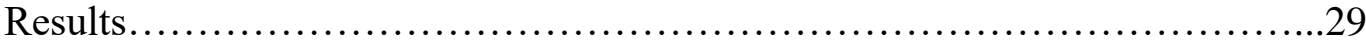

Chapter 5

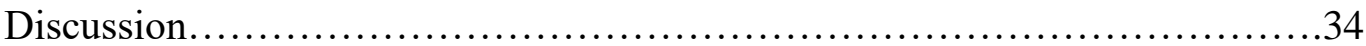

Chapter 6

Conclusion................................................................. 47

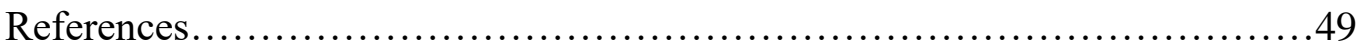

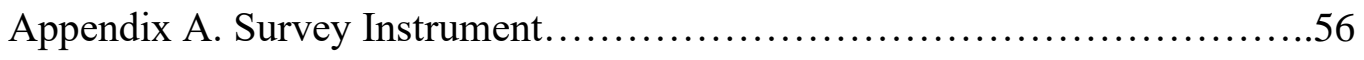

Appendix B. Supplemental Materials.....................................67 


\section{List of Tables}

Table 1: Descriptive Statistics for Scales and Demographics.......................22

Table 2: CDCA Items................................................. 25

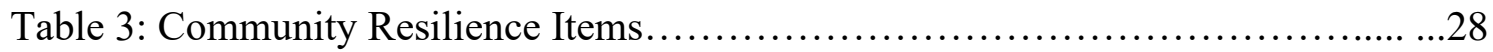

Table 4: CDCA, Neighborhood belonging, and Community Resilience Coefficients...30 


\section{List of Figures}

Figure 1: T-Test Comparing Facebook Members and Non-Members................ 29

Figure 2: Facebook Group Use Tukey Post-Hoc Results......................... 33 


\section{Chapter 1: Introduction}

In the early days of September 2020, several wildfires ravaged communities like Mill City, Estacada, and Oregon City, south of the Portland Metro Area in Oregon. Many of these communities are small, tightknit, and rural with limited local news coverage and limited access to communication resources. Many people were evacuated, and hundreds lost their homes. However, many residents sought connection, distributed information, and offered their services to fellow community members. They came together by utilizing a wide variety of communication resources. Most interestingly, they wielded a vastly understudied communication resource: locally-oriented Facebook groups.

For many communities like Oregon City in the United States, the combination of weather and climate related disasters and the continued decline of local news access is increasingly problematic. In 2017 alone, the United States suffered 16 weather or climate related 'billion-dollar disasters' (National Centers for Environmental Information, n.d.). While they gain national attention, these disasters wreak havoc on local economies as well as the fabric of the local community. Perhaps more concerning is that these disasters are increasing in their scale, frequency, and intensity (Kousky, 2012). As disasters become a normal part of life for more people, local governments and communities have been forced to adopt new approaches to disaster communication.

One of the most important components of disaster response and crisis management is the dissemination of clear and accurate information. When disaster strikes, the threads of the community become stressed, and any weakness in the communication infrastructure of that community are exposed (Ball-Rokeach, 2006). 
Further exacerbating this issue is the overall lack of local news coverage for many communities in the United States. News organizations face increasingly difficult economic dynamics that forced the removal of local bureaus, a reduction in investigative reporting, and a realigned focus on crime, automotive accidents, and national news (Pickard, 2019; Olsen, Pickard, \& Westlund, 2020). The culmination of these forces is an overall decrease in access to robust local news (Abernathy, 2020). During a disaster, information deficits and gaps in local communication infrastructures could have potentially harmful consequences. Therefore, local communities, governments, and local organizations have a vested interest in crafting potential solutions to these ever-increasing issues.

As traditional sources of local news and information decline, community-oriented social media services (e.g., Nextdoor, Facebook groups) are expanding (Masden, Grevet, Grinter, Gilbert, and Edwards, 2014). Thus far, community-oriented social media use remains relatively understudied. Not only do we not understand how citizens utilize these resources, we are also generally unaware of the content that they create and access using them. More specifically, we do not know how these communication resources are wielded in the event of a disaster. Accordingly, the current study has the potential to provide support for the idea that locally-oriented social media usage can compensate for or replace resources that local news organizations can no longer provide.

A survey of residents of Oregon City, OR and its environs, which were impacted by the Oregon wildfires of 2020, was conducted to assess the differences among citizens who use a local Facebook group \& those who do not. This survey includes the Citizen 
Disaster Communication Assessment (CDCA) battery developed by Spialek and Houston (2018) as well as community resilience and neighborhood belonging scales developed by Pfefferbaum, et al. (2015) and Ball-Rokeach, Kim, and Matei (2001). Results indicate that citizens who utilize locally-oriented Facebook groups during and after a disaster exhibited stronger perceptions of community resilience and neighborhood belonging. These results have theoretical implications for CIT and communication ecology research by lending support to the notion that localized social media can contribute positively to the communication action context and storytelling network of a community. They also put forth practical implications for local leaders and organizations by highlighting the need for a revised vision of community communication and disaster response. 


\section{Chapter 2: Literature Review}

\section{Communication Ecologies}

At a basic level, individuals rely on media to achieve certain goals. Thinking more broadly, the Communication Infrastructure Theory (CIT) posits that access to, and the integration of, communication resources allow individuals to achieve community goals. CIT is comprised of two pillars, neighborhood storytelling networks (NSN) and communication action contexts (CAC). Neighborhood storytelling networks are the networked connections between individuals, the local media ecology, and the broader community (Kim \& Ball-Rokeach, 2006). NSNs bind a community through discourse, and they can be conceptualized in many ways. Citizens can read the local newspaper and then discuss news with friends or fellow community members, town hall meetings spur discussion of local issues, or simply neighbors discussing local issues over the fence line. NSNs need a space, physical or virtual, to form. CACs are both the communicative spaces where integration of the NSN occurs, and the overall conditions for storytelling.

For example, CACs can be comprised of parks, community centers, grocery stores, coffee shops, etc. However, CACs also include community variables like poverty rates, internet access, or urbanization. Overall, the $\mathrm{CAC}$ of a community inhibits or allows community storytelling to flourish.

One of the most important aspects of CIT is the level of integration between its components (Kim \& Ball-Rokeach, 2006). Meaning, if citizens, local media, and community organizations are highly integrated, they will each incite the other to tell stories and discuss local issues. For example, if an individual reads a story in their hyper- 
local newspaper, they may discuss it with a friend down the street. This individual-level discussion is beneficial, but the reach of its benefits is short. However, if this individual happens to be the leader of a community organization, the story they read may inspire them to act on a given issue. The three nodes of integration are dependent on each other, and a "missing link" in this model can lead to detrimental effects on access to communication resources, and therefore, potential pro-social outcomes. Another reason for a disconnected storytelling network is a weakened communicative action context. Many communities lack access to well-kept parks, friendly and inviting spaces, and other physical CACs. However, as the internet becomes more accessible to more people, it would behoove CIT scholars to consider how the internet can become a positive contributor to both the CAC and storytelling network of a community (Nah et al., 2021).

Previous research provides empirical support for the importance of integrated storytelling. Ball-Rokeach (2001) and Ball-Rokeach et al. (2001) conducted studies on several communities in Los Angeles, California. They find support for both the higher and lower levels of storytelling integration. Communities with high storytelling integration successfully stimulated storytelling between the three different stakeholders: individuals, local media, and community organizations. Low integration communities were fragmented, meaning, one or more of the stakeholders either lacked presence, or the stories they constructed were not community oriented. These findings suggest that mesolevel local news media may not have the capabilities to cover hyper-local affairs. So, for example, The Oregonian, a newspaper based in Portland, OR does not have enough resources to cover a peripheral community like Oregon City - a relatively small $(\sim 36,000$ 
population) and distant ( 22 miles from Portland) part of the metropolitan area. Therefore, Oregon City affairs go largely uncovered, and citizens do not receive storytelling stimulation from local media.

More recent studies specifically analyze the internet and social media as a distinct piece of a community's storytelling network. Nah et al., (2021) argue that community oriented social media can act as storytelling agent, such as traditional media, and contribute to the overall storytelling network of a community. Further, they found that community oriented social media use contributed to civic participation. This current study furthers Nah et al., (2021) argument by conceptualizing locally-oriented social media as contributing to the communication action context of a community. CACs reflect the conditions for community storytelling. The simplest way to conceptualize this is through communication resources. The more access to communication to resources, the more fruitful the $\mathrm{CAC}$ will be. A more nuanced approach would be to analyze the potential barriers or gateways to communication resources. For example, a lack of physical spaces to tell stories (e.g., Churches, community centers, local businesses, etc.) would act as a barrier to neighborhood storytelling. Thus, these barriers would negatively impact the communication action context of a community (other barriers include natural disasters). Locally-oriented social media are intriguing in that they provide a virtual space, or in other words, a virtual gateway for neighborhood storytelling to occur. This means that locally-oriented social media can itself be a storyteller, but it also serves as the platform, or utility, for users to engage with each other. According to CIT, this would positively add to the communication action context of a community, potentially 
alleviating other detriments to the communication action context, such as natural disasters or a global pandemic.

Additionally, the internet and social media act as potential converging points for other storytelling networks. For example, An and Mediola-Smith (2018) analyzed the potential for Twitter to encourage and develop storytelling networks in a local community. By assessing tweets from a single community, the authors found that simply following another member in the local community and following local media accounts significantly increased discussion about the community on Twitter. These findings have major implications for crafting a potential solution to local communication infrastructure weaknesses in that they establish a relationship between digital communication and place. This highlights the continuing importance of physical community boundaries, and that virtual communication processes have direct impacts in the physical realm.

The rise of social media platforms that incentivize connectedness has reinvigorated CIT researchers. Ognyanova, Ball-Rokeach, An, et al. (2013) conducted a study in which both traditional and new media were examined. They hypothesized, like many others, that local media usage would predict political participation and civic engagement. Furthermore, they predicted that locally-oriented social media and internet use would generate integrated storytelling networks, and therefore generate political and civic engagement. Their findings reflect the current state of affairs. Local news consumption was not related to political participation and civic engagement (Ognyanova, et al. 2013). The authors theorized that this relationship appeared due to the overall lack of access to hyper-local media sources. Contrarily, integrated storytelling through locally- 
oriented social media use positively predicted community integration and political and civic engagement (Ognyanova et al. 2013). This preliminary study highlights the need for updated comparative research between locally-oriented social media usage and traditional media sources. Previous research supports the notion that conversation about one's community generates civic and political participation (Wyatt, Katz, and Kim, 2000). Locally-oriented social media provides an unrestricted platform for dialogue and discussion about local issues. From a CIT perspective, communities with more access or more developed social media networks may develop higher rates of neighborhood belonging and community resilience. On the contrary, recent criticisms of locallyoriented social media argue that these communication platforms can be subjected to racism, misinformation, and fear mongering (Kurwa, 2019). These competing narratives highlight the need for a detailed exploration of locally-oriented Facebook group content. The presented literature on CIT has varying limitations that need to be addressed. First, while most CIT studies have focused specifically on larger neighborhoods in even larger urban cities (Kim \& Ball-Rokeach, 2006), relatively few studies focus on smaller cities that have drastically different local media attributes. Second, while local news organizations continue to dissolve, relatively few (e.g., Ognyanova et al. 2013; Nah et al., 2021) CIT studies have been conducted in our current media environment. More specifically, none have made it their goal to analyze the potential for locally-oriented digital media use to substitute for the lack of hyper-local news.

\section{Disaster Communication Ecologies}


Kim and Ball-Rokeach (2006) argue that citizens utilize neighborhood storytelling networks to share ideas and contribute to the local discourse. During a disaster, citizens are evacuating to nearby towns, property is often destroyed, and the local landscape is permanently altered. In this process, disasters deform the communicative action contexts of a community, and citizens must rely on other storytelling agents, specifically those provided by the internet and media, for communicative action.

\section{The Citizen Disaster Communication Assessment}

Disasters are dynamic events, and thus, researchers must account for this dynamism when measuring various communicative actions. Houston (2012) argues that disasters occur in phases. In their Citizen Disaster Communication Assessment (CDCA), Spialek and Houston (2018) posit that disaster communication can be conceptualized as a cyclical model consisting of the Pre-Event, Event, and Post-Event phases. While these phases stand alone, it is important to note that they can merge into each other (Spialek \& Houston, 2018). For example, conversations between citizens concerning future preventative measure in the Post-Event phase may conceptually merge.

Spialek and Houston (2018) have identified nine different (three in each phase) communication processes that individuals utilize during a disaster ${ }^{1}$. In the Pre-Event phase, individuals utilize communication resources to mitigate potential damage, assess the risk of disasters and their own preparedness for a disaster, and to access disaster mobile apps. In the Event phase, individuals utilize communication processes to connect

\footnotetext{
${ }^{1}$ See Pg. 20 or Appendix A for CDCA items
} 
with family, friends, and neighbors, correct false information about the disaster, and to confirm the status of a disaster. Lastly, individuals in the Post-Event phase interact with communication processes to assist with disaster recovery, tell stories about the disaster, and to promote personal growth.

The CDCA measures individuals' communicative actions during a disaster. Thus, by design, it measures bottom-up communication processes rather than traditional topdown models of disaster communication (e.g., traditional news media, local government, etc.). This allows researchers to measure how effective communities are at engaging citizens during a disaster and allows for the comparison of different information ecologies that are of interest in the current thesis.

Previous models of disaster communication posited by the U.S federal government emphasized top-down, government-centric flows of communication (Federal Emergency Management Agency [FEMA], 2013). These models prioritized government sourced information and relied on traditional media sources, i.e., television news broadcasts, newspapers, etc. for information dissemination and mirrored more traditional theoretical models of communication such as the Two-Step flow (Katz, 1957).

Recent research of disaster communication ecologies highlights a shift from these traditional top-down disaster communication approaches to what FEMA (2011) describes as a Whole Community approach (Spialek \& Houston, 2018). At a basic level, the Whole Community approach encourages a collaborative dialogue between community-oriented actors (e.g., local media, local organizations, etc.) and local governments. This approach 
attempts to localize information dissemination rather than relying on Federal agencies and national organizations to provide information and support.

However, the Whole Community approach underplays micro-level actors (e.g., citizens, hyper-local organizations, and hyper-local media, etc.) and the role that they play during disaster situations. Additionally, the current Whole Community approach is problematic in that it assumes that a community has access to a vibrant local news ecology. As noted by local news scholars and government institutions, (see Shaker, 2014; Hindman, 2011; Pickard, 2019) local news distribution, and thus consumption, is decreasing at a rapid rate. Successful disaster response hinges upon successful disaster communication (CDC, 2014; Covello, 2008), and by relying on crumbling communication infrastructures to disseminate disaster communication, communities are actively put at risk.

Considering the potential impacts of losing a major piece of a communication infrastructure, there is a considerable gap in the research surrounding the efficacy of various communication strategies. Prior research demonstrates the efficacy of traditional top-down media sources (e.g., Television, newspapers) in generating community resilience perceptions during and after a disaster (Houston, Spialek, First, Stevens, and First, 2017). Furthermore, scholars also illustrate the ability of bottom-up communicative actions through social media to build community resilience and develop coping mechanisms (Spialek, Czlapinski, and Houston, 2016; Tandoc \& Takahashi, 2016). However, there is little research that directly compares these two strategies. More specifically, the literature is devoid of research that explores locally-oriented social media 
groups or communities. What we do know is that recent research (see Nah et al., 2021) has identified qualities of social media that lead to positive community outcomes, and thus, these platforms deserve further academic attention. This level of potential communication infrastructure integration is unparalleled by any other communication medium. Therefore, based on the unique attributes of the locally-oriented Facebook group, I pose the following hypothesis:

\section{$H_{1}$ : Participants who belong to locally-oriented Facebook groups will engage in more Citizen Disaster Communication compared to those who do not.}

\section{Communication and Neighborhood Belonging}

Neighborhood belonging, defined as citizen's connections to their fellow residents, and the level of support that those individuals provide to each other (BallRokeach, Kim, \& Matei, 2001), generates positive psychological and behavioral attributes for citizens and their communities (Kim \& Kang, 2010). For example, Kim and Ball-Rokeach (2006b) report that stronger feelings of neighborhood belonging boost collective efficacy and the frequency of civic actions. Similarly, Prezza and Constantini (1998) find that individuals have greater self-confidence and problem-solving abilities if they have a strong sense of community belonging. Based on these findings, elevating perceptions of neighborhood belonging in citizens should be a central goal for local communities, governments, and media.

In disaster contexts, neighborhood belonging becomes even more important. As communities are separated through evacuation orders and geographic destruction, connections to a place and the individuals in that place are difficult to maintain. Neighbors become a valuable resource for citizens as they navigate the disaster and post- 
disaster phases. Some may rely on neighbors for electricity, food, or transportation. Not having these established connections with one's neighbors could cause harm during disasters. One way that citizens can maintain these connections is through various communicative processes outlined in the CDCA. Spialek and Houston (2019) show that greater levels of citizen disaster communication are associated with increased perceptions of neighborhood belonging in the Event and Post-Event disaster phases. However, current gaps in the research highlight the need for a more precise measurement of the communicative processes outlined in the CDCA.

To advise local governments and communities on how to help their citizens cope with disasters, we must gain an understanding of the effectiveness of various communicative mediums in the context of emergencies. Kim and Ball-Rokeach (2006) argue that integration into a storytelling network can drive various pro-social perceptions and behaviors (e.g., civic engagement or neighborhood belonging). Locally-oriented Facebook groups provide a possible medium for this integration. Citizens can use these online forums to discuss local issues, share information, and build a sense of community. The diverse utility of these platforms is more important during a disaster. Citizens can share on-the-ground information, tell stories, and distribute resources on one platform. Rather than compiling various communicative resources, citizens gain access to a "onestop-shop" for infrastructure integration. Thus, citizens could be expected to engage in more disaster and community-oriented conversation during the disaster period. Therefore, I pose the following hypotheses:

\section{$H_{2 a}$ : Citizen disaster communication will be positively associated with perceptions of neighborhood belonging.}




\section{$H_{2 b}$ : Citizens who belong to a locally-oriented Facebook group will report a higher level of neighborhood belonging over citizens who do not belong to a locally-oriented Facebook group.}

\section{Community Resilience}

Community resilience is a "collective activity in which individuals join together" (Pfefferbaum \& Klomp, 2013, p. 279), and addresses collective issues such as disasters or crises (Spialek \& Houston, 2019). While individual resilient actors (families, organizations, etc.) may contribute to community resilience, the true measure of community resilience is in the integration of these individual actors (Acosta, Chandra, and Madrigano, 2017). Thus, the focus of community resilience should be on the collective ability of individuals to communicate and adapt to a community problem (Houston, 2018).

Community resilience is a collective activity, and therefore a proper conceptualization of community resilience must include communication (Nichols, 2012). While previous models of community resilience have recognized the importance of communication processes (see Norris, Stevens, Pfefferbaum, Wyche, \& Pfefferbaum, 2007), few have systematically recognized the centrality of communication to community resilience models (Spialek and Houston, 2019). For example, in Norris and colleague's (2007) model of community resilience, communication is identified as one of the four facets, yet it underlies the other three facets. For example, the facet of social support inherently includes several communicative actions. In an offline setting, one could provide social support by calling a neighbor or family member or by checking in on someone's home during an evacuation. In an online setting, one could repost helpful links 
for their neighbors and family. Regardless, these examples highlight the need for a model of community resilience that centers communication and communicative processes. In response to this need, Houston et al. (2015) conceptualized a model of community resilience that placed communication at the fore. Their model included communication systems and resources, strategic communication processes, community relationships, and community attributes.

Community resilience is both a perceptual and physical experience (Cohen, Leykin, Lahad, Goldberg, \& Aharonson-Daniel, 2013). Conceptualizing the physical experience of community resilience is a difficult task, thus, the importance of understanding the perceptual aspects of community resilience cannot be understated. In order to take real-world action, citizens must first conceptualize (or perceive) their community's strengths, weaknesses, resources, and capacities (Pfefferbaum \& Klomp, 2013). These perceptions are constructed via communicative processes between individuals and their community. Therefore, understanding the relationship between communication and perceptions of community resilience is important to building an understanding of how communities can construct real-world community resilience.

Little research has been conducted that assesses the connection between communication resources and perceptions of community resilience. However, initial results, while slightly unclear, have shown a positive connection. Houston, Spialek, First, Stevens, and First (2017) found that individuals who utilized top-down information sources during a major tornado event in Joplin, Missouri had higher perceptions of community resilience. A study conducted by Spialek, Czlapinski, and Houston (2016) 
showed that increased citizen disaster communication through social media after a series of tornados was associated with an increase in community resilience perceptions. This study highlights the efficacy of bottom-up communicative actions through social media on generating perceptions of community resilience. Individuals who accessed social media and connected with other community members were more likely to describe their community as connected and caring even after controlling for demographic factors Most recently, Spialek and Houston (2019) found that increased disaster communication was associated with increased perceptions of community resilience. If perceptions of community resilience are reliant on elevated communicative processes between individuals and their communities, I pose the following hypotheses:

\section{H3a: Citizens' disaster communication will be positively related to their perceptions of community resilience.}

$H_{3 b}$ : Perceived community resilience will be higher among citizens who belong to locally-oriented Facebook groups than among citizens who do not.

\section{Misinformation}

Despite the possible benefits afforded by local social media use, scholars have expressed concern in understanding how individuals debunk rumors and mitigate the spread of false disaster information online. Hunt, Wang, and Zhuang (2020) conducted a study that measured the spread of rumors relating to Hurricane Harvey and Hurricane Irma on Twitter, as well as rumor control efforts by Twitter users. They found over $85 \%$ of the sampled users who encountered false information would respond by spreading that false information. If they were later presented with debunking information, 78 to $97 \%$ of 
false information spreaders did not remove or edit their posts containing false information.

Perhaps unsurprisingly, the researchers found that Twitter users who produced the most debunking information were official government organizations or verified news outlets such as CNN, The New York Times, or local news organizations. These debunking tweets were then utilized by other Twitter users to further debunk misinformation using URL linking, retweeting, or quoting. These results suggest that individuals who rely on top-down information sources are more likely to debunk false information in a disaster context.

A recent content analysis of tweets related to COVID-19 found that the spread of debunking information lagged behind misinformation (McGlynn, Baryshevtsev, \& Dayton, 2020). During their period of collection, it took seven days for debunking information to overtake misinformation. The researchers argue that this lag-time creates a virtual space for misinformation to spread and become accepted. Similar to Hunt, Wang, and Zhuang's (2020) findings, the researchers found that users cited authoritative sources when presenting debunking information and non-authoritative sources (e.g., 'My friend who is a doctor said') when presenting misinformation.

While local Facebook groups allow for the integration of a community's storytelling networks, they also provide an open medium for the spread of misinformation. The threat of the Oregon wildfires was short lived (September $7^{\text {th }}-$ September $29^{\text {th }}$ ), and therefore the opportunity for debunking information to appear in these Facebook groups was scarce. Furthermore, "belief echoes" left behind by exposure 
to misinformation may reduce the propensity for an individual to correct misinformation (Thorson, 2016). However, affordances of social media, such as comment threads or easy access to information, make it easier for users to correct misinformation. Thus, the literature lacks clear conclusions on this issue, and so any attempt to answer these questions will be exploratory. Because the $\mathrm{CDCA}^{2}$ allows researchers to assess specific communicative actions (including rumor debunking), one can begin to assess the relationship between information resource and the propensity to correct misinformation. Thus, I pose the following research question:

$R_{1}$ : What is the relationship between locally-oriented Facebook group membership and the propensity to correct false disaster information?

\footnotetext{
${ }^{2}$ See Pg. 20 or Appendix A for CDCA sample questions.
} 


\section{Chapter 3: Method}

To analyze the impacts of utilizing local Facebook groups during disasters, I conducted a survey of residents impacted from the September Oregon Wildfires from January $11^{\text {th }}, 2021$ to April $16^{\text {th }}, 2021$. Using Qualtrics, this survey was distributed to residents who live in communities that were impacted by the Beachie Creek, Riverside, and Lionshead fires in lower Clackamas County and parts of Marion County. To determine local Facebook group membership, participants indicated their membership status through questions presented in the survey. In total, the four local Facebook groups ${ }^{3}$ in the area have over 70,000 members, and the total population of these communities is somewhere around 80,000.

\section{Participants}

Participants were included in this project through several different recruitment strategies. Facebook group users $(n=185)$ were recruited through Facebook announcements made within the relevant groups that were periodically sent out during the recruitment period. IRB-approved recruitment messages were developed and posted to the following local Facebook groups: Oregon City Chit Chat, Unite Oregon City, Canby NOW, and Mollala NOW. Recruitment messages were sent out periodically over a -three-month period, and the researcher tried to maintain 2-3-week intervals between each posting. In the end, all four groups received three individual postings. In addition, the researcher snowball sampled on Facebook through his family and acquaintances. The snowball method was conducted by asking family members and friends to share/post the

\footnotetext{
${ }^{3}$ Facebook groups include Oregon City Chit Chat, Unite Oregon City, Canby NOW, and Mollala NOW
} 
recruitment message to their personal Facebook timelines. No specific instructions were given on who to present the message to, and the expectation was that individuals would self-identify as members or non-members of local Facebook groups.

Non-Facebook group users $(n=36)$ were recruited through several boots-on-theground methods including but not limited to: flyers, email blasts through various email listservs, word of mouth, community announcements, and personal connections. For example, participants were recruited from local community colleges, large local employers, and local politicians. Further efforts included paper door hangers placed strategically in neighborhoods throughout various communities. In addition, the author took care to ensure that participants recruited through these methods were directed to the same survey as the Facebook group participants and were recruited from the same communities as the Facebook group members.

After the survey was closed, the dataset was cleaned for analysis by removing respondents who failed to either complete the survey or give it satisfactory attention. First, participants were removed from the sample for not completing at least $50 \%$ of the survey or failing the attention check(s). ${ }^{4}$ The majority of participant removal was due to failed attention checks. Approximately 85 participants failed the attention checks. The remaining participant removal was due to incompletion. "Racers" were not removed from the dataset, as none of the participants fell outside 2.5 standard deviations from the mean

\footnotetext{
${ }^{4} 50 \%$ completion was chosen as the cutoff point because participants who complete $50 \%$ should have completed the media use, Facebook group membership, and CDCA variables. In addition, a 50\% cutoff was utilized to maximize the number of participants in each Facebook membership group. Recruitment for non-Facebook members was particularly difficult, thus, retaining the maximum number of non-members was an important task for this project.
} 
$(M=14.3, S D=11.6)($ Pelham, 2013). 14 participants did not respond to the Facebook membership question and were dropped from the sample. In total, 326 participants took the survey. After data cleaning, the remaining total $N=218$, eliminating 108 participants from the dataset.

Of the total sample, 184 participants identified as members of local Facebook groups while 34 identified as non-members. This large discrepancy serves as a caveat to any conclusions that can be made at the end of the project. While previous scholars (de Winter, 2013) have found that t-tests conducted with relatively small sample sizes should have no detrimental impact on statistical power or the likelihood of making Type I errors, readers should be aware of this discrepancy. Table 1 provides an overview of the final sample. Race and ethnicity varied slightly from the surrounding area, with White people making up $81 \%$ of Clackamas County’s population, Black or African American people making up .8\%, Asian people at 4.5\%, and Hispanic and Latinx people making up 7.62\% (Data USA, 2021). The majority of the sample identified as Female $(n=154,77 \%)$. Over half of the sample (51.2\%) had obtained a College degree (Associate's - Doctorate). 66\% of the sample had an annual household income over $\$ 70,000$. The average age of the sample was $46(S D=15)$. 
Table 1

Descriptive Statistics for Independent/Dependent Variable Scales and Demographics

Demographic

Frequencies

\section{Percent of}

Frequency Total

\section{Gender}

Men

Women

45

$22.5 \%$

154

$77 \%$

$\underline{\text { Race/Ethnicity }}$

White

Hispanic/Latinx

Multi-racial

182

$92.4 \%$

$5 \quad 2.5 \%$

$6 \quad 3 \%$

Age

Mean $=46 \quad$ Std. Dev $=14.37$

Facebook Use

Non-users

34

58

$15.5 \%$

Infrequent Users

Frequent Users

123

$26.6 \%$

$56.4 \%$

Variable Descriptives

CDCA

Community Resilience

Neighborhood Belonging

Mean

Std. Dev.

Cronbach's

2.82

.69

Alpha

3.40

.62

.96

3.39

.91

.94

3.27

.75

.81

CDCA Event

2.52

.76

CDCA Post-Event

2.52 


\section{Procedures}

Following recruitment, participants were directed to an online Qualtrics survey through an anonymous link or QR code. Participants were assessed on the Event and Post-Event phases of the CDCA, as well as perceptions of neighborhood belonging and community resilience ${ }^{5}$. In addition to these measures, participants were asked several demographic questions, traditional news media use and exposure questions, as well as questions regarding their membership and usage of local Facebook groups. As an incentive to participate, at the end of the survey participants were asked to vote for the placement of a $\$ 250$ charitable contribution to a local organization that aids those impacted by wildfires ${ }^{6}$. A charitable contribution was chosen to incentivize participation for three reasons. One, since these fires are a very localized event, and participants were very likely impacted themselves, the charitable donation builds a sense of trust and connection between the researchers and the participants. Two, it serves to give back directly to the participants and their community without requiring large grants or external funding. Lastly, it gives the gives the participants a sense of purpose for completing the survey.

\section{Measures}

\section{Citizen Disaster Communication}

All participants were asked to complete the questions from the Event and PostEvent sections of the CDCA (see Appendix A) developed by Spialek and Houston (2018). Various communicative actions were measured using a 5-point Likert scale with

\footnotetext{
${ }^{5}$ See Table 3 or Appendix A for Community Resilience items.

${ }^{6}$ The Oregon Red Cross received the most votes at 68.
} 
responses ranging from 1 (Never engaged in this activity) to 5 (Always engaged in this activity). The Event and Post-Event sections of the CDCA are respectively split into sections. A Cronbach's Alpha reliability test indicates that the scale is highly reliable (26 items; $\alpha=.96$ ). In addition, the subscales for the Event and Post-Event were adequately reliable (12 items; $\alpha=.88 ; 14$ items; $\alpha=.90)$. Descriptive statistics for the CDCA can be found in Table 1.

To answer $\mathrm{RQ}_{1}$, the Correcting section of the CDCA will be used to measure the propensity to correct inaccurate disaster information. Since this section specifically addresses communicative actions that seek to correct inaccurate information, this subsection of the CDCA is appropriate for answering $\mathrm{RQ}_{1}$. 
Table 2

CDCA Items

During and after the wildfires, did you...

\section{Correcting}

Correct a disaster rumor?

Encourage someone to not spread rumors about the disaster?

Encourage someone to correct inaccurate information about the disaster?

Correct inaccurate information about the disaster?

\section{Connecting}

Let someone know you experienced the disaster?

Let someone know you were safe?

Talk to someone to confirm whether reports about the disaster were true?

Comfort someone during the disaster?

Confirming

Look for information to confirm whether reports about the disaster were true?

Look for information to find out what was going on during the disaster?

Receive a disaster warning?

Assisting

Look for information on how to help disaster survivors?

Talk with someone about what to donate to help disaster survivors?

Talk with someone about where to make donations to help disaster survivors?

Talk with someone about the importance of volunteering after the disaster?

Look for information on what to donate to help disaster survivors?

Talk with someone about how to make a donation to a disaster relief organization?

\section{Growing}

Talk with someone about how growth can result from a disaster?

Encourage someone to think of the good things that happened because of the disaster?

Talk with someone about how something good resulted from the disaster?

Encourage someone to someone to view the disaster in a positive way?

Storytelling

Listen to someone tell stories about the disaster?

Told stories about the disaster?

Told stories about my experience following the disaster? 
Neighborhood Belonging

Perceptions of neighborhood belonging were assessed using a four-item scale developed by Ball-Rokeach, Kim, and Matei (2001). Responses to each item were measured using a 5-point Likert scale with responses ranging from 1 (strongly disagree) to 5 (strongly agree). Items are: 'You are interested in knowing what your neighbors are like;' 'You enjoy meeting and talking with your neighbors;' 'It's easy to become friends with your neighbors;' and 'Your neighbors always borrow things from you or your family'. A Cronbach's Alpha test indicated the scale as sufficiently reliable (4 items; $\alpha=$ .81). Descriptive statistics for this scale can be found in Table 1 .

\section{Community Resilience}

Community resilience perceptions were measured using the Communities Advancing Resilience Toolkit (CART) (see Table 3 or Appendix A) developed by Pfefferbaum et al. (2015). Participants were asked to indicate how well 23 community resilience statements accurately describe their community. Responses to each statement range from 1 (strongly disagree) to 5 (strongly agree). The CART includes five domains of community resilience: connection and caring, transformative potential, resources, disaster management, and information and communication. Example items can be found

in Table 3. A Cronbach's Alpha reliability test indicates the scale to be highly reliable (23 items; $\alpha=.94)$. Descriptive statistics for the CART can be found in Table 1.

\section{Facebook Group Use}

In addition to FB group membership, Facebook group use was measured using a standard media use question on a 5-point Likert type scale. To parse Facebook group usage into non-user, infrequent use, and frequent use groups, a grouping variable was 
computed in SPSS. The non-user group consisted of $n=34$ participants, the infrequent use group consisted of $n=58$ participants and included participants who reported using FB groups less than once per week, once per week, and 2-3 times per week. The frequent use group had $n=123$ participants and included participants who reported using FB groups 4-6 times per week or every day. 
Table 3

Community Resilience Items

Thinking about your community at a broad level, indicate your agreement with the following...

Connection and Caring

People in my community feel like they belong to the community.

People in my community are committed to the well-being of the community.

People in my community have hope about the future.

People in my community help each other.

My community treats people fairly no matter what their background is.

Resources

My community supports programs for children and families.

My community has resources it needs to take care of community problems.

My community has effective leaders.

People in my community are able to get the services they need.

People in my community know where to go to get things done.

Transformative Potential

My community works with organizations and agencies outside the community to get things done.

People in my community communicate with leaders who can help improve the community.

People in my community work together to improve the community.

My community looks at its successes and failures so it can learn from the past.

My community develops skills and finds resources to solve its problems and reach its goals.

My community has priorities and sets goals for the future.

Disaster management

My community tries to prevent disasters.

My community actively prepares for future disasters.

My community can provide emergency services during a disaster.

My community has services and programs to help people after a disaster.

\section{Information and Communication}

My community keeps people informed about issues that are relevant to them.

If a disaster occurs, my community provides information about what to do.

I get information/communication through my community to help with my home and work life.

People in my community trust public officials. 


\section{Chapter 4: Results}

Hypothesis 1 posits that participants who belong to locally-oriented Facebook groups will engage in more Citizen Disaster Communication compared to those who do not. An independent samples t-test was conducted to determine the mean difference between members and non-members of locally-oriented Facebook groups and their respective levels of citizen disaster communication. Members of local Facebook groups $(M=2.86, S D=.66)$ demonstrated significantly higher levels, $t(219)=-2.16, p=.026, \eta^{2}$ $=.022$, of citizen disaster communication than non-members $(M=2.61, S D=.69)$ (see Figure 1). Thus, the first hypothesis was supported.

\section{Figure 1}

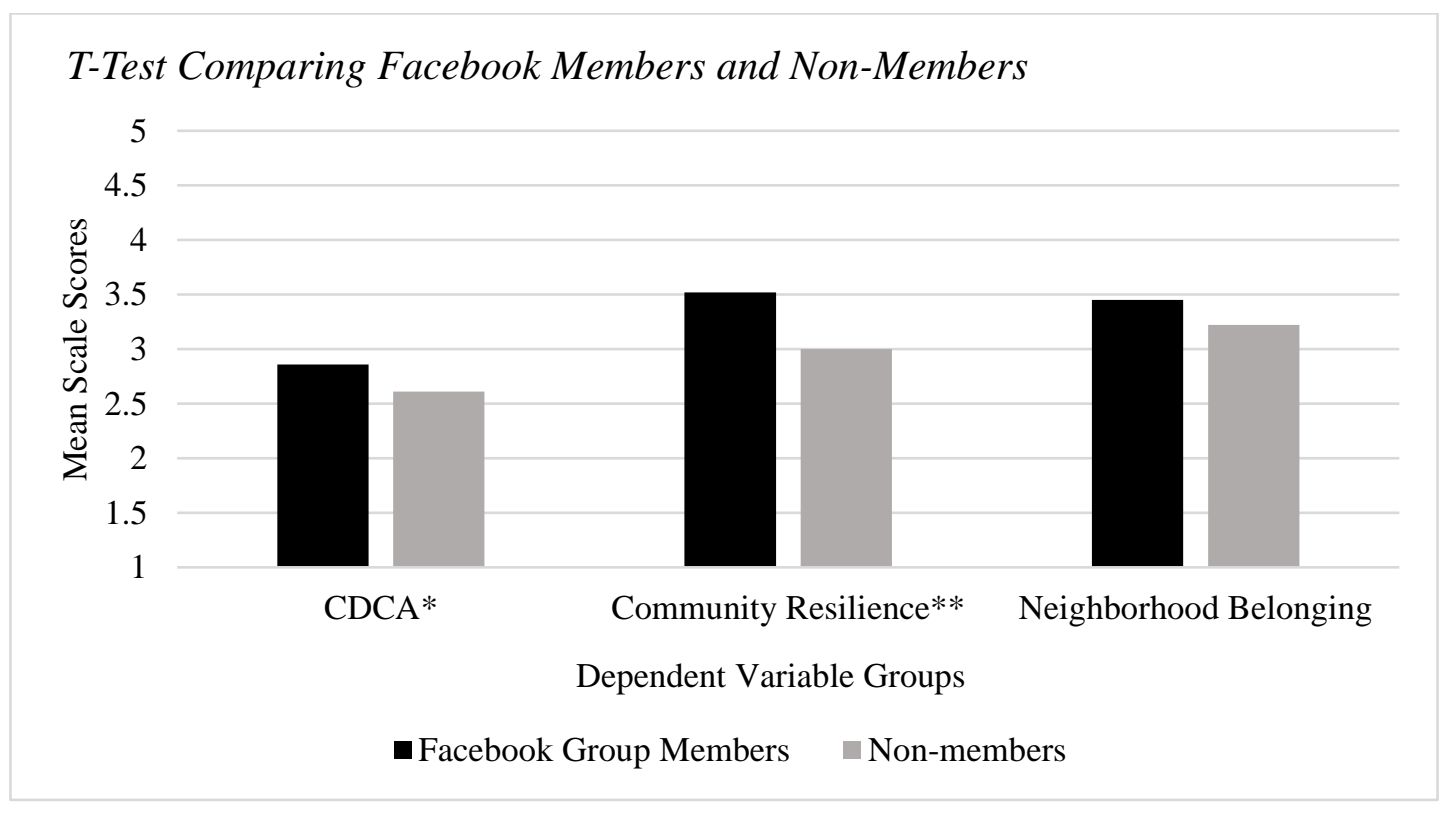

Note: * indicates significance at $p<.05 . * * *$ indicates significance at $p<.001$

Hypothesis 2a argues that higher levels of citizen disaster communication will be positively associated with perceptions of neighborhood belonging. Pearson Correlations statistics were calculated to determine the association between citizen disaster 
communication and neighborhood belonging perceptions. Results indicate the entire CDCA model is significantly positively correlated $r(213)=.332, p<.01$. with perceptions of neighborhood belonging (see Table 4). In addition, both the Event, $r(213)=.326, p<$ .01 , and Post-Event, $r(213)=.297, p<.01$, phases were significantly positively correlated to neighborhood belonging perceptions (see Table 4). Hypothesis 2a was supported. ${ }^{7}$

\section{Table 4}

CDCA, Neighborhood belonging, and Community Resilience Correlation Coefficients

\begin{tabular}{|c|c|c|}
\hline & Neighborhood Belonging & Community Resilience \\
CDCA & $r=.332^{* *}$ & $r=.249^{* *}$ \\
CDCA Event & $r=.326^{* *}$ & $r=.178^{* *}$ \\
CDCA Post-Event & $r=.297^{* *}$ & $r=.284^{* *}$ \\
\hline
\end{tabular}

Note: $* *=p<.01$.

Hypothesis $2 \mathrm{~b}$ posits that individuals who belong to locally-oriented Facebook groups will exhibit greater perceptions of neighborhood belonging than those who do not.

\footnotetext{
${ }^{7}$ A correlation table containing all the individual communicative factors found in the CDCA was computed. Out of the six CDCA variables, all were significantly correlated to neighborhood belonging perceptions (see Table 6 in Appendix B).
} 
An independent samples t-test was conducted to determine the mean difference between members and non-members of locally-oriented Facebook groups and their respective perceptions of neighborhood belonging. Results indicate that members of locally-oriented Facebook groups $(M=3.45, S D=.89)$ did not demonstrate significantly higher perceptions of neighborhood belonging, $t(213)=-1.38, p=.13$, over non-members $(M=$ $3.22, S D=.87$ ) (see Figure 1). Hypothesis $2 \mathrm{~b}$ was not supported.

Hypothesis $3 \mathrm{a}$ posits that greater citizen disaster communication will be positively associated with perceptions of community resilience. Similar to the approach to Hypothesis 2a, two separate Pearson correlation tables were computed to determine the association between citizen disaster communication and community resilience. The first correlation indicates that overall citizen disaster communication is positively associated with perceptions of community resilience, $r(209)=.249, p<.001$ (see Table 4). Splitting the CDCA model into its respective sections, both the Post-Event, $r(209)=.284, p<$ .001 , and Event, $r(209)=.178, p=.009$, phases were significantly positively correlated to community resilience perceptions (see Table 4). Hypothesis 3 a was supported. ${ }^{8}$

Hypothesis $3 \mathrm{~b}$ posits that citizens who belong to locally-oriented Facebook groups will exhibit significantly greater perceptions of community resilience compared to non-member citizens. An independent samples t-test was conducted to analyze the mean score difference between members and non-members and their perceptions of community resilience. Results indicate that members of locally-oriented Facebook groups $(M=3.52$,

\footnotetext{
${ }^{8}$ The final correlation table contains all of the individual CDCA variables, and results indicate that three variables, are significantly associated with perceptions of community resilience (see Table 5 in Appendix B).
} 
$S D=.60)$ demonstrated significantly higher community resilience perceptions, $t(209)=-$ $4.60, p<.001, \eta^{2}=.072$, compared to non-members $(M=3.00, S D=.64)$ (see Figure 1$)$. Hypothesis $3 b$ was supported.

Research question 1 asks about the relationship between local Facebook group membership and the propensity to correct disaster misinformation. In a similar vein to the comparison hypotheses, an independent samples t-test was conducted to determine a difference in the propensity to correct disaster information between members and nonmembers of local Facebook groups. Results indicate no significant differences between members $(M=2.64, S D=1.18)$ and non-members $(M=2.37, S D=1.21)$ and their propensity to correct disaster misinformation, $t(214)=-1.22, p=.223$.

\section{Supplementary Analysis}

To further explore H1, 2B, and 3B, three ANOVAs and Tukey Post-hoc analyses were computed. Rather than separating the participants with the Facebook group membership variable, these analyses were organized using a more detailed Facebook usage variable. The two Facebook variables together allowed participants to be split into three respective groups: Non-users $(n=34)$, infrequent users $(n=58)$, and frequent users $(n=123)$. Results from the one way ANOVAs indicate significant group differences with respect to citizen disaster communication, $\left[F(2,212)=3.35, p=.037, \eta^{2}=.03\right]$, and community resilience $\left[F(2,202)=8.48, p<.001, \eta^{2}=.077\right]$.

To gain further insight into the nature of these differences, a Tukey Post-hoc analysis was conducted (see Figure 2). Specifically, this analysis allows researchers to identify specific group differences. Results indicate that frequent users $(M=2.92, S D=$ 
.68) reported significantly higher levels of citizen disaster communication, $p=.03$, than non-users $(M=2.60, S D=.67)$. In addition, High users $(M=3.56, S D=.62)$ reported significantly higher levels of community resilience, $p<.001$, than non-users $(M=3.07$, $S D=.60)$. Of note, infrequent users $(M=3.46, S D=.56)$ also reported significantly higher levels of community resilience, $p=.009$, than non-users $(M=3.07, S D=.60)$.

Correlation analyses also support the linear relationship depicted by the ANOVA: Facebook group usage is positively correlated with citizen disaster communication, $r(121)=.190, p=.01$. Additionally, Facebook group use was associated with both the Event, $r(172)=.205, p=.006$, and Post-Event, $r(182)=.161, p=.03$, versions of the CDCA. The only other media use variable significantly associated with any of three dependent variables was local TV news usage, which was positively associated with community resilience, $r(134)=.179, p=.04$.

\section{Figure 2}

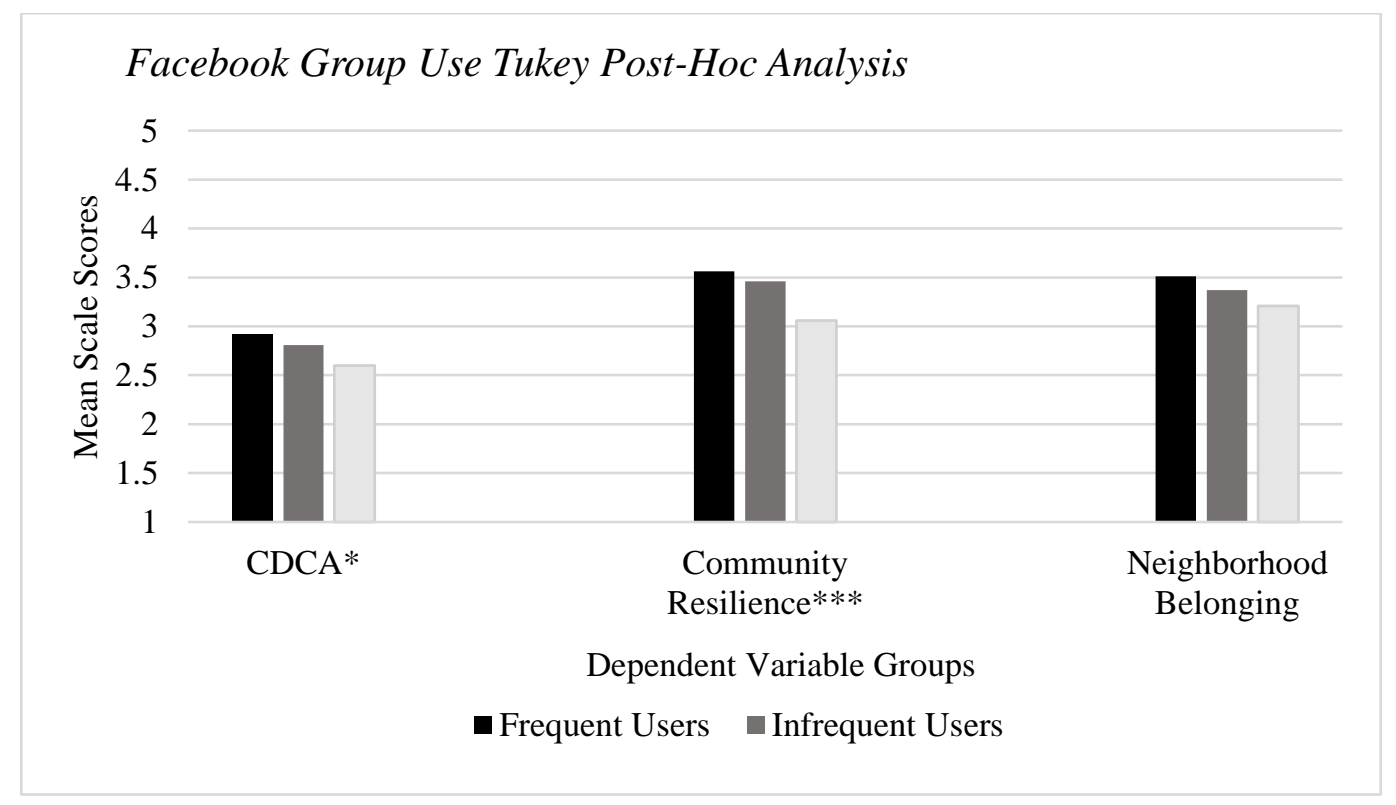

Note: * indicates significance at $p<.05$ level. *** indicates significance at $p<.001$ level. 


\section{Chapter 5: Discussion}

This project expands the current understanding of the relationship between goaloriented citizen disaster communication ecologies, perceptions of community resilience, and neighborhood belonging. In addition, this project helps illuminate ways that communities can improve disaster outcomes by leveraging a relatively new communication resource: locally-oriented Facebook groups. Results indicate that more citizen disaster communication in the Event and Post-Event phase is significantly related to perceptions of community resilience and neighborhood belonging. Furthermore, members of locally-oriented Facebook groups exhibited more disaster communication and had greater perceptions of community resilience compared to non-members.

These results reinforce theoretical models that position communication as an important factor in fostering community resilience, in addition to supporting previous introductory research in this field (e.g., Spialek \& Houston, 2019). In addition, these results support previous CIT and neighborhood belonging research (e.g., Kim \& BallRokeach, 2006, Kim \& Kang, 2010) as well as research exploring disaster communication ecologies utilizing CIT (e.g., Spialek \& Houston, 2019). While further establishing the relationship between communication and pro-social outcomes, this project puts forth a strategy to increase communication in communities. Specifically, this study explores the potential utility of locally-oriented Facebook groups to expand citizen disaster communication. At a basic level, these results support the notion that locallyoriented social media groups are associated with positive community outcomes, thus, 
local governments, leaders, and organizations should strive to develop and support the creation and usage of these platforms.

\section{Local Social Media Ecologies}

The primary goal of this project was to unearth some potential remedies to the local communication ecology crisis. As previous scholars (Kim \& Ball-Rokeach, 2006) note, community's communication ecologies are essential to fostering pro-community outcomes. Scholars (Spialek \& Houston, 2019) note a distinct form of communication ecology that arises during disasters. While these two ecologies are different, they are impacted by the same external factors. The continued loss of local communication resources, and flaws in current disaster communication approaches has left many communities with weakened communication ecologies. While solutions to this crisis come in many forms, this study offers some evidence to suggest that localized usage of social media can be beneficial to communities and their citizens during a disaster.

Results from the current study support the argument that members of locallyoriented Facebook groups have higher levels of citizen disaster communication and greater perceptions of community resilience. These findings are important for two reasons. First, these findings expand upon CIT, potentially positing localized social media as a contributor to both the neighborhood storytelling network, and communication action context of a community. Communication action contexts serve as barriers or gateways for community storytelling. Context can be set in various ways, but one of the most obvious ways is overall access to communication resources. Communities with less access to communication resources may have weakened CACs. Locally-oriented 
Facebook groups positively contribute to a CAC by providing communication resources with less barriers than traditional media resources. Thus, locally-oriented Facebook groups should be considered a gateway for community storytelling. Additionally, they also can serve as a storytelling agent in a community. Meaning, not only do these groups provide access to storytelling resources, but they also serve as their own distinct storytelling medium. Users can access information while simultaneously providing information to other users. Thus, these groups provide both the structure (CAC) and network (NSN) for community storytelling. For example, perhaps a community lacks a strong a local news network; however, they can retrieve information and share stories via locally-oriented Facebook groups. We could reasonably expect that community to be better able to respond to disasters than a similar community with no local Facebook groups.

Second, these results establish a connection between the internet and geographic space. For years, scholars have wondered whether the internet, a space with no geographic anchor, could be connected to a seemingly geographically created space, a city or community. At best, these results highlight that online membership in a webbased, geographically local, social media platform can generate pro-community outcomes.

Results from the current study reiterate the importance for Event and Post-Event citizen disaster communication. As Spialek and Houston (2019) found in their data, Event and Post-Event disaster communication were important for inspiring perceptions of community resilience and neighborhood belonging. Thus, to support their results, this 
project also examined the CDCA in both Event and Post-Event form. As highlighted in the results, Event and Post-Event CDCA sections were positively significantly associated with both community resilience and neighborhood belonging. These results provide concurrent validity for the CDCA, and they highlight that the CDCA can be used in various contexts.

While these results seem promising, there is a scenario in which the highlighted findings are a result of individual demographic differences rather than changes brought upon by retaining membership in local Facebook groups. While this project cannot establish causal relationships, the supplementary analysis conducted should shed some additional insight into these relationships. While it is expected that High users of local Facebook groups would report higher levels of citizen disaster communication and community resilience, it was interesting to find that low-medium users also reported higher levels of community resilience over non-users. Perhaps these results indicate that the perceived benefits from local Facebook group membership are indeed related to actual usage of the Facebook groups rather than other demographic factors.

The media use variables collected in this project can also further explain the proposed relationships. Facebook group usage was only positively associated with citizen disaster communication variables. Thus, it appears that citizen disaster communication may act as a mediating variable between Facebook group usage and perceptions of community resilience and neighborhood belonging. In a sense, this finding aligns with previous CDCA research, and it highlights an important goal of citizen disaster communication research. To achieve the perceived benefits that citizen disaster 
communication can bring, researchers and local leaders need to find ways to increase that level of communication. In the case of this project, it would appear that local Facebook groups have this potential. However, future research should seek to establish causal data, as this project can only assess correlational relationships.

Curiously, Facebook group members did not demonstrate significantly higher perceptions of neighborhood belonging over non-members. To gain some further insight into this finding, a Post-Hoc analysis was conducted to better understand other forms of media use and their relationship to neighborhood belonging. Of note, newspaper subscriptions were significantly related to neighborhood belonging. This finding highlights a potential pitfall of local social media in that it indicates a disconnect between local Facebook groups and the geographic area that they virtually represent. Perhaps the function of local news; stories about the community for the community, grants it a unique ability to inspire connection between neighbors. Contrarily, this finding may indicate a demographic difference rather than other explanations. Someone who goes out of their way to find and subscribe to local newspapers may represent a subset of the population that is extremely connected to the community. Thus, it may be their inherent connection to the community that is driving their newspaper subscription, rather than the opposite. Future research should further explore what specific communication resources influence neighborhood belonging.

Preparing for Future Disasters and Lessons Learned from COVID-19

Among the other social, cultural, and economic factors that inhibit or expand communication infrastructures, the shifts caused by the COVID-19 pandemic should be 
explored by CIT researchers. As employers, governments, and other organizations recognize the economic and convenience benefits of remote working, worshipping, and policymaking, community members may spend significantly less time interacting with individuals outside of their household. While these dynamics may not take shape, they have certainly accelerated present trends. Thus, CIT researchers should begin to reconsider what is to be operationalized as a storytelling network or communication action context. For example, conversations after a Church event, or lunch-break discussions of local matters may not occur with the same pre-pandemic frequency. Applying the traditional conceptualizations of NSNs and CACs may find communities with severely weakened communication infrastructures. Fortunately, the current study supports locally-oriented social media as a storytelling agent, and potentially as a CAC. Thus, I echo recent calls made by Nah et al., (2021) to expand CIT to include locallyoriented social media as distinct pieces of communities' communication infrastructure.

Not only will this reframing of locally-oriented social media aide in postpandemic life, it could better prepare communities for future disasters. As argued previously, disasters disrupt the CACs and NSNs of a community. In most disasters, evacuations, physical damage, and infrastructure damages may disrupt communication resources. While not completely impenetrable, cell and internet services are a fairly robust communication resource, and they may be heavily relied upon during a disaster. As most social media platforms are accessible by phone, these platforms should be considered valuable disaster communication storytelling agents. 
Furthermore, these results indicate the potential utility of localized social media as we progress further and further into the digital age. While previous researchers (e.g., Masden et al., 2014) has identified the oftentimes racist and hate filled uses of platforms such as Nextdoor, this research illustrates the potential positive uses and associated positive outcomes of locally-oriented social media. Thus, scholars should seek to the understand the ways in which we can bend platform usage for the better.

Although the current study is one of a few projects who have tackled local social media usage, these results indicate a promising future for these platforms in disaster contexts. However, these platforms are not without their issues. Firsthand experience with these locally-oriented groups or Nextdoor neighborhood groups will immediately alert the user to the myriad issues these platforms face. Rumors, misinformation, racism, etc. spread with limited accountability. In some instances, the groups may impose rules and staff moderators to maintain civility, but even those measures are not always enough. The disaster period in which this project collected data for became nationally known for instances of false information and fearmongering that were birthed on these very platforms. Future research should then assess different ways to make these platforms more welcoming, equitable, and hospitable to marginalized communities.

While results were significant for the potential benefits of these Facebook groups, results for the misinformation research question were non-significant. Thus, we cannot determine how misinformation fits into the dynamic between local Facebook groups and its users. Future researchers should specifically assess levels of misinformation present in these Facebook groups and determine how those levels impact the proposed benefits 
found in the current study. Overall, future research should attempt to analyze the content of these groups. While the CDCA captures what participants believe to be Storytelling or Assisting, it cannot determine how this communication materializes in local Facebook groups and the broader community conversation. Thus, future researchers should conduct in-depth content analyses utilizing the CDCA framework to understand how the communicative actions outlined in the CDCA unfold in context.

In addition, qualitative methods should be utilized to gain a more nuanced understanding of the proposed relationships. During the data collection period, the researcher was contacted by a few different participants who wanted to speak more about their experience using local social media groups during the disaster. In these conversations it was noted that local Facebook groups were extremely valuable to these individuals, and they described the various ways in which these groups aided their disaster response and recovery efforts. They also expressed concern with the micro and meso-level government response and communication efforts, citing the local Facebook groups as their main information source after becoming frustrated with other sources. Based on these insights, there is much to learn about local communication ecologies and their intersection with social media platforms through interviews and other qualitative methods.

\section{Practical Implications}

While the results of this project provide compelling theoretical and empirical contributions, it also provides practical use to communities at risk of disasters. This project provides further validity for the CDCA, which can be used in non-academic 
settings to benefit communities. As noted previously, the current Whole Community approach lacks micro-level, bottom-up communication assessment, and the CDCA in its current state can provide insight into this activity (Spialek \& Houston, 2019). Furthermore, local governments and community organizations alike can use the CDCA to 'take stock' of local communication assets and the degree to which its constituents are contributing to the local communication ecology. The CDCA can also be used to assess communication campaigns or communication strategies in development (Spialek \& Houston, 2019). This is especially important for risk and crisis communication, where pre-planning and strategizing is paramount for successful disaster communication (CDC, 2014; Coombs, 2009). In addition, the CDCA has now been tested in different geographic and cultural locations, indicating that its use in various communities should remain valid. However, further research should explore the use of the CDCA in extremely rural communities and communities with a more diverse population.

Beyond assessment implications, the current project maintains that interpersonal communication is one of the most important factors for successful crisis management. Results from this study support previous research that indicates communication as in important facet for developing pro-community perceptions. Thus, the simple solution to increasing positive disaster outcomes is to promote communication amongst community members. This solution is not straightforward, however, and as noted above there are less and less opportunities for individuals to interact and discuss community matters. In the context of the COVID-19 pandemic, these opportunities are even less abundant. Simultaneously, Facebook and other platforms provide endless opportunities for 
communication, however the community must be well-connected in the first place for local Facebook groups to flourish. Thus, local municipalities and community organizations should encourage and support the development of local community social media pages. Rather than developing the pages themselves, these structural entities should serve a marketing or recruitment function. Government-run pages run the risk of censorship perceptions or other deterrents to open participation, however promoting the page on the County website may increase participation.

From a structural perspective, local governments should encourage the development of the technological infrastructures that allow these forms of communication to flourish. As scholars have noted (Cullen, 2001), there are still a significant number of people in the United States without internet or smart-phone access. Without these tools, individuals will not be able to access the benefits that these platforms can provide. While promoting these pages and inspiring their growth is important, ensuring fair and equitable access to them is of equal importance. Learning from the COVID-19 pandemic, and as we prepare for potential future pandemics, local governments and organizations need to consider how to foster community communication without relying on physical space. During the process of drafting this thesis, the surveyed communities experienced long-power outages from a winter ice storm. Simultaneously, the pandemic limited gatherings, or in other words, limited the potential communication action contexts of these communities. Of note, those who had cell service or had the social and financial mobility to seek electrified shelter once again flocked to local Facebook groups to share resources, track PGE workers, and give 
updates on power outages etc. While this was promising to witness, it starkly highlighted the digital and economic divide that is ever present in communities across the nation.

\section{Limitations}

As with all scientific research, the current project has its limitations. First, this project is cross-sectional, and thus causal inferences cannot be made. Perhaps, the members of these groups joined because they already felt a sense of connection and resiliency with their community. The very nature of the groups may attract communityminded individuals, thus, their scores appeared higher than non-members. However, some communities present in this survey have local Facebook groups with near ubiquitous membership, for example, Oregon City has a population of about 35,000, and the largest Facebook group, Oregon City Chit Chat, has about 33,000 members. Accounting for non-resident members and non-active users, this group still represents a majority of the local population. Thus, it would appear that these groups attract the entire community and encourage membership. Future research should address this issue by identifying communities with and without local Facebook groups to conduct comparative analyses.

Second, the current study analyzed perceptions of neighborhood belonging and community resilience rather than quantifiable actions. Therefore, this project cannot determine if individuals are converting their perceptions into actions. As Spialek and Houston (2019) note, these perceptions can be conflated with outcomes. Scholars suspect that individuals who perceive and connect to their community is positive ways will perform the work to foster community resilience. However, there is a reality in which 
these perceptions do not carry behavioral weight and may in fact cause complacency within the community (Spialek \& Houston, 2019). Future research needs to address these relationships and determine a method of operationalizing and measuring community outcomes.

Third, the discrepancy in the member and non-member groups utilized in both the T-tests and ANOVAs is potentially problematic. While the member group should have a sufficient sample size, the relatively smaller non-member group may struggle to adequately capture a 'normal' non-member. Meaning, the sample of non-members may not be representative of the non-member population. Thus, the findings present in this project could be attributed to individual demographic differences rather than being associated with Facebook group membership and usage.

Finally, the current study utilized convenience samples for its analyses and sampling methods. Thus, the results from this study cannot be generalized to all individuals who experience disasters. Although these results are not generalizable, it adds to a list of successful case studies supporting the applicability of the CDCA (see Spialek \& Houston, 2019; and Spialek \& Houston, 2018). Of note, sampling non-Facebook members became a tedious task. If anything, the struggle to identify and recruit these individuals indicates a few unique aspects of these communities. One, it shows substantial membership rates in communities who possess local Facebook groups. This is promising in that it implies enthusiasm for local Facebook groups, and that these individuals perceive them as a useful communication resource. Future research should further explore how individuals perceive and relate to these local Facebook groups. Two, 
it highlights disparities in communication access. Perhaps individuals who do not belong to local Facebook groups simply do not have access to them. In turn, these individuals are inherently difficult to access because they cannot access technological resources that the survey was disseminated through. Thus, future research should seek to recruit individuals without the technological or economic infrastructure to access local Facebook groups. 


\section{Chapter 6: Conclusion}

As recently highlighted by researchers from the San Jose State University Fire Weather Research Laboratory (2021), there are many areas around the country face record breaking dry seasons and greater risk of wildfires. As a result, fire risks are at an all-time high. As these warnings are echoed across the country, congregating in the West Coast, it is apparent that the risk of severe wildfires is only increasing. Other climate crises, such as hurricanes, floods, etc. are following similar trends. Simultaneously, communities continue to struggle with disaster response and recovery, and are consistently left without strong communication infrastructures. While the future may seem bleak for our most vulnerable communities, research such as the current study present promising results for government, communities, and individuals alike.

As we look to combat these issues, local governments and community organizations should seek to evolve the ways in which they conceptualize disaster communication. While top-down approaches such as the Whole Community approach, or strategies found in the CDC CERC manual provide valuable insights, the current study further supports the notion that bottom-up, micro-level communication between individuals has a profound association with a community's resilience and sense of belonging. Thus, top-down community actors should seek to inspire this type of communication between their constituents.

Besides changing their philosophy, the current study supports a "retooling" of communities' communication infrastructures. The COVID-19 pandemic has highlighted flaws in solely relying on physical space for communicative interaction, and disasters 
further exacerbate these issues. As social media platforms continue their ascension into public life, and traditional forms of communication disappear, community leaders should seek to learn how to utilize these new tools to increase resident-to-resident communication before, during, and after a disaster. While other solutions undoubtedly exist, the current study identifies localized social media platforms as effective catalysts for community communication and resilience. 


\section{References}

Abernathy, P. (2020). Expanding News Deserts | UNC Center for Innovation \& Sustainability in Local Media. The Expanding News Desert. Retrieved November 5, 2020, from https://www.usnewsdeserts.com/

Acosta, J., Chandra, A., \& Madrigano, J. (2017). An agenda to advance integrative resilience research and practice: Key themes from a resilience roundtable. Santa Monica, CA: RAND Corporation.

An, Z., \& Mendiola-Smith, L. (2018). Mapping Communication Infrastructure Theory Onto Twitter: Network Integration and Neighborhood Storytelling. International Journal of Communication, 12(0), 21.

Ball-Rokeach, S. J., Kim, Y.-C., \& Matei, S. (2001). Storytelling Neighborhood: Paths to Belonging in Diverse Urban Environments. Communication Research, 28(4), 392-428. https://doi.org/10.1177/009365001028004003

Bean, H. (2018). National resilience. Journal of Applied Communication Research, 46, 23-25. doi:10. 1080/00909882.2018.1426709

Bonanno, G. A., \& Diminich, E. D. (2013). Annual research review: Positive adjustment to adversity - trajectories of minimal-impact resilience and emergent resilience. Journal of Child Psychology and Psychiatry, 54, 378-401. doi:10.1111/jcpp.12021

Buzzanell, P. M., \& Houston, J. B. (2018). Communication and resilience: Multilevel applications and insights. Journal of Applied Communication Research, 46, 1-4. doi:10.1080/00909882. 2017.1412086 
Cohen, O., Goldberg, A., Lahad, M., \& Aharonson-Daniel, L. (2017). Building resilience: The relationship between information provided by municipal authorities during emergency situations and community resilience. Technological Forecasting and Social Change, 121, 119-125. doi:10.1016/j.techfore.2016.11.008

Coombs, W. T. (2009). Conceptualizing crisis communication. In R. L. Heath \& H. D. O’Hair (Eds.), Handbook of risk and crisis communication (pp. 99-118). New York: Routledge. doi:10.4324/9780203891629.ch5

Covello, V. T. (2008). Strategies for overcoming challenges to effective risk communication. In R. L. Heath and H. D. O'Hair (Eds.), Handbook of risk and crisis communication (pp. 143-167). New York: Routledge. doi:10.4324/9780203891629.c

Federal Emergency Management Agency [FEMA]. (2011). A whole community approach to emergency management: Principles, themes, and pathways for action. Washington, DC: U.S. Department of Homeland Security.

Federal Emergency Management Agency [FEMA]. (2013). National strategy recommendations: Future disaster preparedness. Washington, DC: U.S. Department of Homeland Security.

Hindman, M. (2011). Less of the same: The lack of local news on the internet. Federal Communications Commission.

Houston, J. B. (2018). Community resilience and communication: Dynamic interconnections 
between and among individuals, families, and organizations. Journal of Applied Communication Research, 46(1), 19-22.

https://doi.org/10.1080/00909882.2018.1426704

Houston, J. B., Spialek, M. L., First, J., Stevens, J., \& First, N. L. (2017). Individual perceptions of community resilience following the 2011 Joplin tornado. Journal of Contingencies and Crisis Management, 25(4), 354-363.

https://doi.org/10.1111/14685973.12171

Hunt, K., Wang, B., \& Zhuang, J. (2020). Misinformation debunking and cross-platform information sharing through Twitter during Hurricanes Harvey and Irma: a case study on shelters and ID checks. Natural Hazards (Dordrecht), 103(1), 861-883. https://doi.org/10.1007/s11069 020-04016-6

Katz, E. (1957). The two-step flow of communication: An up-to-date report on an hypothesis. Public opinion quarterly, 21(1), 61-78.

Kim, Y.-C., \& Ball-Rokeach, S. J. (2006). Civic Engagement From a Communication Infrastructure Perspective. Communication Theory, 16(2), 173-197. https://doi.org/10.1111/j.1468-2885.2006.00267.x

Kim, Y. C., \& Kang, J. (2010). Communication, neighbourhood belonging and household hurricane preparedness. Disasters, 34, 470-488. doi:10.1111/j.03613666.2009.01138.x

Kim, Y. C., \& Ball-Rokeach, S. J. (2006). Community storytelling network, neighborhood context, and civic engagement: A multilevel approach. Human Communication Research, 32(4), 411-439. 
Kousky, C. (2014). Informing climate adaptation: A review of the economic costs of natural disasters. Energy Economics, 46, 576-592. https://doi.org/10.1016/j.eneco.2013.09.029

Kurwa, R. (2019). Building the Digitally Gated Community: The Case of Nextdoor. Surveillance \& Society, 17(1/2), 111-117. https://doi.org/10.24908/ss.v17i1/2.12927

Masden, C. A., Grevet, C., Grinter, R. E., Gilbert, E., \& Edwards, W. K. (2014). Tensions in scaling-up community social media: A multi-neighborhood study of nextdoor. Proceedings of the 32nd Annual ACM Conference on Human Factors in Computing Systems - CHI '14, 32393248. https://doi.org/10.1145/2556288.2557319

McGlynn, J., Baryshevtsev, M., \& Dayton, Z. A. (2020). Misinformation more likely to use non-specific authority references: Twitter analysis of two COVID-19 myths. Harvard Kennedy School Misinformation Review. https://doi.org/10.37016/mr$\underline{2020-37}$

Nah, S., Kwon, H. K., Liu, W., \& McNealy, J. E. (2021). Communication infrastructure, social media, and civic participation across geographically diverse communities in the United States, Communication Studies.

National Centers for Environmental Information [NCEI]. (n.d.). Billion-dollar U.S. weather and climate disasters: Overview. Retrieved from: http://www.ncdc.noaa.gov/billions/

Nicholls, S. (2012). The resilient community and communication practice. Australian 
Journal of Emergency Management, The, 27(1), 46.

Norris, F. H., Stevens, S. P., Pfefferbaum, B., Wyche, K. F., \& Pfefferbaum, R. L. (2007). Community resilience as a metaphor, theory, set of capacities, and strategy for disaster readiness. American Journal of Community Psychology, 41, 127-150.

Ognyanova, K., Chen, N.-T. N., Ball-Rokeach, S. J., An, Z., Son, M., Parks, M., \& Gerson, D. (2013). Online Participation in a Community Context: Civic Engagement and Connections to Local Communication Resources. International Journal of Communication, 7(0), 24.

Oh O, Agrawal M, Rao HR (2013) Community intelligence and social media services: a rumor theoretic analysis of tweets during social crises. Mis Q 37(2):407-426

Olsen, R. K., Pickard, V., \& Westlund, O. (2020). Communal News Work: COVID-19 Calls for Collective Funding of Journalism. Digital Journalism, 1-8.

Pelham, B. W. (2013). Intermediate statistics: A conceptual course. Sage.

Pfefferbaum, R. L., \& Klomp, R. W. (2013). Community resilience, disasters, and the public's health. In F. G. Murphy (Ed.), Community engagement, organization, and development for public health practice (pp. 275-298). New York, NY: Springer.

Pfefferbaum, R. L., Pfefferbaum, B., Nitiéma, P., Houston, J. B., \& Van Horn, R. L. (2015). Assessing Community Resilience: An Application of the Expanded CART Survey Instrument With Affiliated Volunteer Responders. American Behavioral Scientist, 59(2), 181-199. https://doi.org/10.1177/0002764214550295 
Pickard, V. (2019). Democracy without Journalism?: Confronting the Misinformation Society. In Democracy without Journalism? Oxford University Press.

Prezza, M., \& Costantini, S. (1998). Sense of community and life satisfaction: Investigation in three different territorial contexts. Journal of community \& applied social psychology, 8(3), 181194.

San Jose State University Fire Weather Research Laboratory. (2021). Retrieved from: https://blogs.sjsu.edu/newsroom/tag/fire-weather-research/

Shaker, L. (2014). Dead Newspapers and Citizens' Civic Engagement. Political Communication, 31(1), 131-148. https://doi.org/10.1080/10584609.2012.762817

Spialek, M. L., Czlapinski, H. M., \& Houston, J. B. (2016). Disaster communication ecology and community resilience perceptions following the 2013 central Illinois tornadoes. International Journal of Disaster Risk Reduction, 17, 154-160. https://doi.org/10.1016/j.ijdrr.2016.04.006

Spialek, M. L., \& Houston, J. B. (2018). The Development and Initial Validation of the Citizen Disaster Communication Assessment. Communication Research, 45(6), 934-955. https://doi.org/10.1177/0093650217697521

Spialek, M. L., \& Houston, J. B. (2019). The influence of citizen disaster communication on perceptions of neighborhood belonging and community resilience. Journal of Applied Communication Research, 47(1), 1-23. https://doi.org/10.1080/00909882.2018.1544718

Tandoc, E. C., \& Takahashi, B. (2017). Log in if you survived: Collective coping on 
social media in the aftermath of Typhoon Haiyan in the Philippines. New Media \& Society, 19(11), 1778-1793. https://doi.org/10.1177/1461444816642755

Thorson, E. (2016). Belief Echoes: The Persistent Effects of Corrected Misinformation. Political Communication, 33(3), 460-480. https://doi.org/10.1080/10584609.2015.1102187

Vosoughi S, Roy D, Aral S (2018) The spread of true and false news online. Science 359(6380):1146-1151

Wyatt, R. O., Katz, E., \& Kim, J. (2000). Bridging the spheres: Political and personal conversation in public and private spaces. Journal of communication, 50(1), 7192. 


\section{Appendix A}

\section{Survey Instrument}

Q59

Were you apart of the Level 1, 2, or 3 evacuation zones at any time as a result of the Oregon Wildfires? Here is a map for reference.

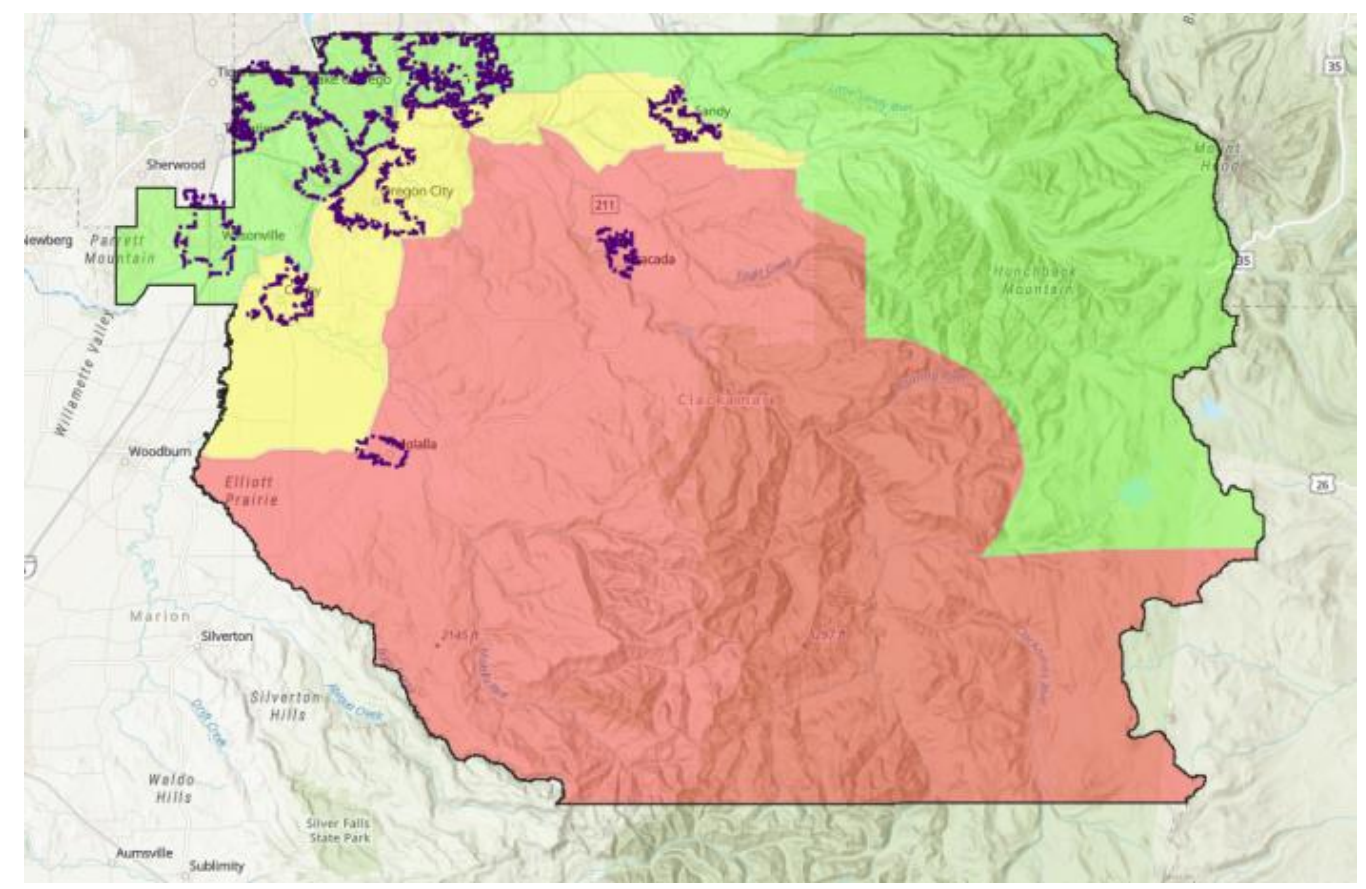

Green $=$ Level 1

Yellow = Level 2

Red $=$ Level 3

Q60 Did you provide support to anyone in the Level 1, 2, or 3 evacuation zones? 
Q85 The following questions will ask you about your use of information sources to access local information/news.

Q81 Do you subscribe to any newspapers?

Q88 Do you use any social media platforms to access local news and information?

Q82 Which newspapers do you subscribe to? Please type all publications you subscribe to in the text box below.

Q89 Which social media platforms do you use to access local news and information? Please type each platform in the box below.

Q68 Did you belong to any local Facebook groups during and after the 2020 wildfires?

Local Facebook groups can be defined as any Facebook group that is rooted in your geographic community (e.g. Oregon City Chit Chat)

Q90 What sources do you use to access local news and information? Please select all that apply. 
Q96 What is your most important source of local news and information?

Q91 How often do you watch Local Television news?

Q92 How often do you read online or print newspapers for local news and information?

Q93 How often do you listen to the radio or podcasts for local news and information?

Q94 How often do you use social media for local news and information?

Q95 How often do you discuss local news and information word-of-mouth?

Q69 Which local Facebook groups do you belong to? Please type the name of each group in the box below.

Q70 How often do you use these Facebook groups? 
Q71 What is your primary use for these Facebook groups?

Q3 Next, we will ask you to answer questions related to actions you took during and after the wildfires. Please indicate how often you engaged in each activity.

Q4 During and after the Oregon wildfires, did you...

Correct a disaster rumor?

Encourage someone not to spread rumors about the wildfires?

Encourage someone to correct inaccurate information about the wildfires?

Correct inaccurate information about the wildfires?

Let someone know you experienced the wildfires?

Let someone know you were safe during the wildfires?

Talk to someone to confirm whether reports about the wildfires were true? 


\section{Q98}

Please continue thinking about actions you took during and after the wildfires. During and after the Oregon wildfires, did you...

Talk with
someone to
see if they
were OK
after the
wildfires?
Comfort
someone
during the
wildfires?
Look for
information
to confirm
whether
reports about
the wildfires
were true?
Look for
information
to find out
what was
going on
during the
disaster?
Receive a
disaster
warning?
Look for
information
on how to
survivors?

Q75

During and after the Oregon wildfires, did you... 
Talk with someone about what to donate to help wildfire survivors?

Talk with someone about where to make donations to help wildfire survivors?

Talk with someone about the importance of volunteering after the wildfires?

Look for information on what to donate to help wildfire survivors?

Talk with someone about how to make a donation to a disaster relief organization?

Talk with someone about how something good resulted from the wildfires taking place? 
Q99

Please continue thinking about actions you took during and after

During and after the Oregon wildfires, did you...

Talk with
someone
about how
growth can
result from a
disaster?
Encourage
someone to
think of the
good things
that happened
because of
the wildfires?
Please select
"often
engaged in
this activity"
here.
Encourage
someone to
view the
wildfires in a
positive way?
Tell stories
about the
wildfires?
Tell stories
about your
experience
following the
wildfires?
Listen to
someone tell
stories about
the wildfires?


Q55 This section asks you to describe your relationship with your neighbors and community.

Please indicate your level of agreement with each statement.

$$
\begin{gathered}
\text { You are } \\
\text { interested in } \\
\text { knowing } \\
\text { what your } \\
\text { neighbors are } \\
\text { like. } \\
\text { You enjoy } \\
\text { meeting and } \\
\text { talking with } \\
\text { your } \\
\text { neighbors. } \\
\text { It's easy to } \\
\text { become } \\
\text { friends with } \\
\text { your } \\
\text { neighbors. } \\
\text { Your } \\
\text { neighbors } \\
\text { always } \\
\text { borrow } \\
\text { things from } \\
\text { you or your } \\
\text { family. }
\end{gathered}
$$


Q25 This section asks you to think about your community on a broad level.

Please indicate your level of agreement with each statement.

People in my community feel like they belong to the community.

People in my community are committed to the well-being of the community.

People in my community have hope about the future.

People in my community help each other.

My community treats people fairly no matter what their background is.

My community has resources it needs to take care of community problems (resources include, for example, money, information, technology, tools, raw materials, and services).

People in my community know where to go to get things done.

My community works with organizations and agencies outside the community to get things done.

People in my community communicate with leaders who can help improve the community. 
Q79 Still thinking about your community on a broad level, please indicate your agreement with the following statements.

My community looks at its successes and failures so it can learn from the past.

My community develops skills and finds resources to solve its problems and reach its goals.

My community tries to prevent disasters.

My community can provide emergency services during a disaster.

My community has services and programs to help people after a disaster.

My community keeps people informed (for example, via television, radio, newspaper, internet, phone, neighbors) about issues that are relevant to them.

If a disaster occurs, my community provides information about what to do.

\section{I get}

information/communication through my community to help with my home and work life.

People in my community trust public officials. 
Q64 Please describe your living situation.

Q63 What city do you currently reside in?

Q65 How many months have you lived in (insert city)?

Q49 What is your gender identity?

Q50 What year were you born?

Q51 With what race/ethnicity(s) do you identify?

Q86 What is your political ideology?

Q52 What was your annual household income in 2020?

Q54 Indicate your highest level of education.

Q97

You have reached the conclusion of this survey. Thank you for taking the time to participate. We appreciate your feedback very much.

As a token of our gratitude, please select a charity from the list below. The charity with the most votes will receive a $\$ 250$ donation. Once again, thank you. 


\section{Appendix B}

\section{Supplemental Materials}

\section{Table 5}

\section{Individual CDCA Variables and Community Resilience Correlation Coefficients}

\begin{tabular}{llrrrrrrr}
\hline & & $\begin{array}{c}\text { Communityr } \\
\text { esilience }\end{array}$ & Storytelling & Growing & Assisting & Correcting & Connecting & Confirming \\
\hline Community Resilience & Pearson Correlation & 1 & $.149^{*}$ & $.152^{*}$ & $.248^{* *}$ & .120 & .070 & .103 \\
& Sig. (2-tailed) & & .017 & .015 & .000 & .057 & .268 & .103 \\
& $\mathrm{~N}$ & 254 & 254 & 254 & 254 & 254 & 254 & 254 \\
\hline \multirow{2}{*}{ Storytelling } & Pearson Correlation & $.149^{* *}$ & 1 & $.287^{* *}$ & $.370^{* *}$ & $.398^{* *}$ & $.659^{* *}$ & $.491^{* *}$ \\
& Sig. (2-tailed) & .017 & & .000 & .000 & .000 & .000 & .000 \\
& $\mathrm{~N}$ & 254 & 273 & 273 & 273 & 266 & 266 & 265 \\
\hline Growing & Pearson Correlation & $.152^{*}$ & $.287^{* *}$ & 1 & $.479^{* *}$ & $.364^{* *}$ & $.311^{* *}$ & $.305^{* *}$ \\
& Sig. (2-tailed) & .015 & .000 & & .000 & .000 & .000 & .000 \\
& $\mathrm{~N}$ & 254 & 273 & 274 & 274 & 267 & 267 & 266 \\
\hline Assisting & Pearson Correlation & $.248^{* *}$ & $.370^{* *}$ & $.479^{* *}$ & 1 & $.467^{* *}$ & $.466^{* *}$ & $.391^{* *}$ \\
& Sig. (2-tailed) & .000 & .000 & .000 & & .000 & .000 & .000 \\
& $\mathrm{~N}$ & 254 & 273 & 274 & 281 & 274 & 274 & 273 \\
\hline Correcting & Pearson Correlation & .120 & $.398^{* *}$ & $.364^{* *}$ & $.467^{* *}$ & 1 & $.432^{* *}$ & $.345^{* *}$ \\
& Sig. (2-tailed) & .057 & .000 & .000 & .000 & & .000 & .000 \\
& $\mathrm{~N}$ & 254 & 266 & 267 & 274 & 274 & 274 & 273 \\
\hline Connecting & Pearson Correlation & .070 & $.659^{* *}$ & $.311^{* *}$ & $.466^{* *}$ & $.432^{* *}$ & 1 & $.710^{* *}$ \\
& Sig. (2-tailed) & .268 & .000 & .000 & .000 & .000 & 274 & .000 \\
& $\mathrm{~N}$ & 254 & 266 & 267 & 274 & 274 & 274 & 273 \\
\hline Confirming & Pearson Correlation & .103 & $.491^{* *}$ & $.305^{* *}$ & $.391^{* *}$ & $.345^{* *}$ & $.710^{* *}$ & 1 \\
& Sig. (2-tailed) & .103 & .000 & .000 & .000 & .000 & .000 & 273 \\
& $\mathrm{~N}$ & 254 & 265 & 266 & 273 & 273 & 273 \\
\hline
\end{tabular}

*. Correlation is significant at the 0.05 level (2-tailed).

*** Correlation is significant at the 0.01 level (2-tailed). 
Table 6

\section{Individual CDCA Variables and Neighborhood Belonging Correlation Coefficients}

\begin{tabular}{|c|c|c|c|c|c|c|c|c|}
\hline & & Storytelling & Growing & Assisting & Correcting & Connecting & Confirming & $\begin{array}{l}\text { Neighborho } \\
\text { od belonging }\end{array}$ \\
\hline \multirow[t]{3}{*}{ Storytelling } & Pearson Correlation & 1 & $.287^{* *}$ & $.370^{* * *}$ & $.398^{* *}$ & $.659^{* *}$ & $491^{* *}$ & $.264^{* *}$ \\
\hline & Sig. (2-tailed) & & .000 & .000 & .000 & .000 & .000 & .000 \\
\hline & $\mathrm{N}$ & 273 & 273 & 273 & 266 & 266 & 265 & 260 \\
\hline \multirow[t]{3}{*}{ Growing } & Pearson Correlation & $287^{* *}$ & 1 & $479^{\text {** }}$ & $364^{* *}$ & $311^{* *}$ & $.305^{* *}$ & $.130^{*}$ \\
\hline & Sig (2-tailed) & .000 & & .000 & .000 & .000 & .000 & .036 \\
\hline & $\mathrm{N}$ & 273 & 274 & 274 & 267 & 267 & 266 & 261 \\
\hline \multirow[t]{3}{*}{ Assisting } & Pearson Correlation & $.370^{* *}$ & $479^{* *}$ & 1 & $467^{* *}$ & $466^{* *}$ & $.391^{* *}$ & $288^{* *}$ \\
\hline & Sig. (2-tailed) & .000 & .000 & & .000 & .000 & .000 & .000 \\
\hline & $\mathrm{N}$ & 273 & 274 & 281 & 274 & 274 & 273 & 261 \\
\hline \multirow[t]{3}{*}{ Correcting } & Pearson Correlation & $398^{* *}$ & $.364^{* *}$ & $467^{* *}$ & 1 & $432^{* *}$ & $.345^{* *}$ & $297^{* *}$ \\
\hline & Sig. (2-tailed) & .000 & .000 & .000 & & .000 & .000 & .000 \\
\hline & $\mathrm{N}$ & 266 & 267 & 274 & 274 & 274 & 273 & 261 \\
\hline \multirow[t]{3}{*}{ Connecting } & Pearson Correlation & $.659^{* *}$ & $311^{* *}$ & $466^{* *}$ & $432^{* *}$ & 1 & $.710^{* *}$ & $240^{* *}$ \\
\hline & Sig. (2-tailed) & .000 & .000 & .000 & .000 & & .000 & .000 \\
\hline & $\mathrm{N}$ & 266 & 267 & 274 & 274 & 274 & 273 & 261 \\
\hline \multirow[t]{3}{*}{ Confirming } & Pearson Correlation & $491^{* *}$ & $.305^{* *}$ & $.391^{* *}$ & $.345^{* *}$ & $.710^{* *}$ & 1 & $210^{* *}$ \\
\hline & Sig. (2-tailed) & .000 & .000 & .000 & .000 & .000 & & .001 \\
\hline & $\mathrm{N}$ & 265 & 266 & 273 & 273 & 273 & 273 & 261 \\
\hline \multirow{3}{*}{$\begin{array}{l}\text { Neighborhood } \\
\text { belonging }\end{array}$} & Pearson Correlation & $264^{* *}$ & $.130^{*}$ & $.288^{* *}$ & $297^{* *}$ & $.240^{* *}$ & $210^{* *}$ & 1 \\
\hline & Sig. (2-tailed) & .000 & .036 & .000 & .000 & .000 & .001 & \\
\hline & $\mathrm{N}$ & 260 & 261 & 261 & 261 & 261 & 261 & 261 \\
\hline
\end{tabular}

**. Correlation is significant at the 0.01 level (2-tailed)

*. Correlation is significant at the 0.05 level (2-tailed) 